\title{
Sheet metal forming using environmentally benign lubricant
}

\author{
Wojciech Więckowski ${ }^{1}$ Janina Adamus ${ }^{1}$ [D $\cdot$ Marcin Dyner $^{2}$
}

Received: 13 December 2019 / Revised: 23 March 2020 / Accepted: 7 April 2020 / Published online: 30 April 2020

(c) The Author(s) 2020

\begin{abstract}
Sheet metal forming belongs to one of the most important technologies enabling the production durable but quite lightweight metal parts. The quality of the drawn parts depends on the deformed sheet metal, applied forming technology and process parameters, such as contact pressure, relative velocity, temperature or lubrication. The forming of steel (1.4021) parts using benign lubricant is analysed. The paper proposes replacing conventional mineral/synthetic lubricants with ones based on vegetable oils and boric acid. The effectiveness of the lubricants was assessed in laboratory strip drawing and cupping tests, and in production. An oil-based lubricant with an additive of boric acid is very effective in reducing frictional resistance and protecting the forming tools against galling.
\end{abstract}

\section{Graphic abstract}

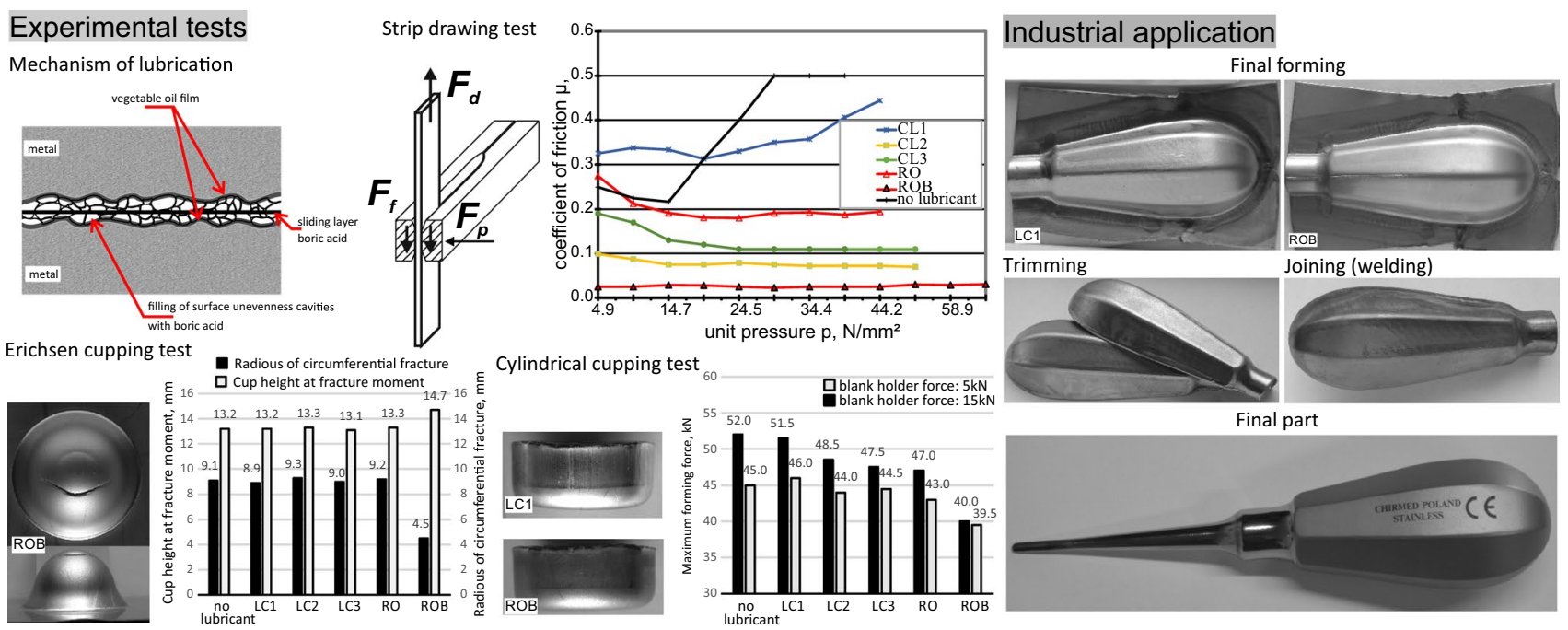

Keywords Sheet metal forming $\cdot$ Steel sheet $\cdot$ Lubrication $\cdot$ Rapeseed $\cdot$ Oil boric acid

Janina Adamus

janina.adamus@gmail.com

Wojciech Więckowski

wieckowski@itm.pcz.pl

Marcin Dyner

m.dyner@chirmed.pl

1 Czestochowa University of Technology, ul. Dabrowskiego 69, 42-201 Czestochowa, Poland

2 CHIRMED Manufacturer of Surgical and Medical Instruments, ul. Mstowska 8A, 42-240 Rudniki-Czestochowa, Poland

\section{Introduction}

Metal working is one of the oldest technologies known to humankind. Gronostajski et al. [1] discussing the latest development trends in metal forming mention sheet forming as a process enabling the production of lightweight sheet metal components, especially desired by the transport industry, for which weight reduction and in consequence energy savings are especially important. This issue is equally 
important in other industries such as in medicine where the weight of surgical instruments is important for surgeons during lengthy operations. Sheet forming allows such large parts as automotive car bodies or plane components, and small ones like beverage cans or metal haberdashery to be produced.

Sheet metal forming is a process in which a sheet blank is formed between forming tool parts (a die, a blank holder and a punch) into a final product by modifying the sheet geometry without removing any material. During forming there is relative movement of the sheet on the tool surface, which generates friction forces and they in turn are responsible for strain inhomogeneity, local necking and even fracture. Adamus [2] emphasizes that the significant proximity of the collaborating surfaces and low relative velocity during forming promote transfer of the deformed sheet material to the tool surface, which initiates wear. In [3], the author indicates that the growth and accumulation of build-up on the tool surface cause scratches and dents on the drawn part surface, which are difficult to remove in subsequent operations. The author believes that the selection of lubricants for sheet metal forming must take into account not only the type of technological process, but also the type of material of the friction pair. To produce high-quality sheet metal products, it is necessary to understand and control the friction conditions in the forming process. In fact, the friction conditions vary during forming depending on the actual process parameters such as pressure, temperature, velocity etc. Lubrication seems to be one of the most efficient ways to control friction and wear. Wilson [4] underlines that better understanding of tribological fundamentals can result in better lubrication systems and process models. The main goal of lubrication is to minimize friction and reduce wear, prevent excessive heating as well as protect against corrosion. Liquid and solid lubricants are the most frequently used in sheet metal forming. Generally, sheet metal forming lubricants are classified into four groups. Consistent with [5] they are as follows: waterbased, oil-based, synthetic-based and solid-based lubricants. Unfortunately, as Lovell et al. [6] noticed, oil-based lubricants typically used in sheet metal forming introduce large amounts of pollutants into the environment and often carry a health risk to humans both during the forming processes and in their utilization. Lubricant performance is usually improved with additives endowing new properties or compensating for the weaknesses of the base oils. According to [7] they are: antioxidants, corrosion inhibitors, dispersing and extreme pressure agents or viscosity modifiers. Chalk, talc, graphite, zinc sulphide and non-ferrous metal powders are the most commonly used additives. A wide range of works has been done on the possibility of improving the tribological properties of the base oils by introducing metal oxide nanoparticles such as copper, zinc, zirconium and titanium as well as borides and sulphides, e.g. molybdenum disulphide, tungsten disulphide and hexagonal boron nitride. Studies of many researchers prove that $\mathrm{CuO}$ nanoparticles effectively reduce both the coefficient of friction (COF) and wear during metal forming processes. Pena-Paras et al. [8] examined the effect of introducing $\mathrm{CuO}$ and $\mathrm{TiO}_{2}$ nanoparticles into polymeric lubricant. Azman et al. [9], in turn, investigated tribological properties of palm oil with additive of $\mathrm{CuO}$ nanoparticles. One explanation of antiwear mechanism is attributed to the deposition of $\mathrm{CuO}$ nanoparticles on the worn surface, which might decrease the shearing stress. Mosleh et al. [10] showed that the dispersion of $\mathrm{MoS}_{2}, \mathrm{WS}_{2}$ and hexagonal boron nitride (hBN) solid nanoparticles in commercial sheet metal forming fluids improves the tribological properties during the forming sheets not only of carbon steel, but also of titanium.

Some researchers claim that the tribological properties of lubricants are affected by such parameters as: size, shape and concentration of nanoparticles. Although authors like [11] or [12] show a clear correlation between tribological performance and parameters such as: particle morphology, their size and concentration, according to [13] the issue of how the shape and size of nanoparticles contribute to achieving anti-friction and anti-wear performance is still not known. Shahnazar et al. [14] also noted that despite several decades of study on nanoparticle additives, the understanding of their tribological behaviour is far from complete. Some aspects such as preparing and maintaining homogenous mixtures of nanostructure particles and oils increased lubricant viscosity because of high particle concentrations, which in turn lead to increased power consumption by the machines, and high production costs still need to be solved [15]. In [16], the authors summarized what have been studied in recent years in nanolubrication and provided some guidance for future design of effective and environmentally friendly lubricants. In [17], the researchers investigated the influence of the blending of graphene with alumina nanoparticles, while in [18] the blending of multiwalled carbon nanotubes with alumina-based nanoparticles in different volumetric concentrations on tribological properties of lubricants for machining AISI 304 stainless steel. The studies showed that the wear and coefficient of friction decrease with an increase in the nanoparticle concentration.

Rao et al. [19] and Bay et al. [20] emphasize that lubricants with extreme pressure (EP) and anti-wear (AW) additives are particularly dangerous. Although these additives facilitate the creation of a lubricant boundary layer on the tool surface, they do not completely prevent tool wear. When using such additives as phosphorus, sulphur or chlorine compounds, it should be kept in mind that their chemical activity may initiate corrosion mechanisms, i.e. accelerate tool or sheet metal damage as well as lead to pollution. Moreover, Zainal et al. [21] believe that when developing lubricants for metal forming, it should be remembered that in contrast 
to machine lubrication, where the lubricant operates in a closed loop system, in metal forming there is an open loop system, which uses much more technological lubricant. In sheet metal forming, after each forming operation a new portion of lubricant must be delivered to the friction pair. A large part of the lubricant is consumed irretrievably, namely it is "taken" by the deformed material and remains on the drawn part. Then, the lubricant is usually removed from the drawn part surface. All surface treatment processes prior to the application of varnish coatings require this. Lovell et al. [6] state that the costs associated with disposing of forming lubricants are increasing exponentially. Therefore, in recent years, there has been a tendency to replace conventional technological lubricants with "green" ones [22] and to reduce lubricant use to the necessary minimum [23]. The term "green lubricants" is generally used for lubricants produced from vegetable oils or other natural resources. Although a lack of lubrication is desirable, its absence usually means intensive tool wear. That is why research is underway to limit the use of lubricants containing harmful substances and replacing them with ecological lubricants [24] is in progress. In [25], the minimum quantity lubrication (MQL) technique for the nano-finishing of AISI 4340 steel using boric acid dissolved in the cutting emulsion was successfully applied. The authors underline that boric acid is an environmentally friendly lubricant and MQL significantly reduces the amount of cutting fluid. The studies presented in [26] prove that mineral and synthetic oils usually used in sheet metal forming operations can be successfully replaced with vegetable ones, even when galvanized steel sheets are stamped. The presence of long fatty acid chains enables effective separation of tool/workpiece interfaces under boundary friction regimes. Additionally, these oils provide sufficient corrosion protection (according to [26] indoor exposure tests show 16 weeks without red rust for bare steel sheets, while the car manufacturers specifications require only 12 -week exposure) and what more vegetable oils are harmless and biodegradable (according to [27], in the same period of time vegetable oils are $80 \%$ degraded, whereas mineral oils only in 15-20\%). Moreover, Padgurskas et al. [27] indicate that in the case of rapeseed oil there is a possibility of improvement low oxidation stability by the addition of natural antioxidants provided that the right manufacturing technology is used. Syahir et al. [28] think likewise that bio-based lubricants exhibit superior tribological properties over conventional mineral lubricants, and add that renewability and biodegradability are their strongest point. Woma et al. [29] overview recent research on vegetable oils as base oil for the production of industrial lubricants, focusing on perspectives and efforts to overcome the related challenges. The authors of [30] confirmed the suitability of environmentally friendly lubricants based on vegetable oils with the addition of boric acid $\left(\mathrm{H}_{3} \mathrm{BO}_{3}\right)$ in forming titanium sheets, while Erdemir et al. [31] observed its suitability in forming aluminium sheets. Boric acid, similar to graphite, molybdenum disulphide and tungsten disulphide, belongs to lamellar solids that have been found to be an effective lubricant. This effectiveness results from their low friction and shear strength values. As reported in [32], the shear strength of boric acid has been experimentally determined to be $23 \mathrm{MPa}$, and its coefficient of friction in ambient temperature has been measured to be less than 0.02 . These values are comparable to the more frequently used molybdenum disulphide, whose shear strength was determined to be $24 \mathrm{MPa}$.

The authors of [33] and [34] claim that surface texturing of the sheet metal or tool can improve lubrication and control friction in deep drawing applications, while the authors of [35] propose using an antiadhesive coating on the tool surface to protect against galling in case of breaking of the lubricant film. For environmentally friendly sheet metal forming, the authors of [36] suggest using diamond like carbon (DLC) coatings for tools while authors of [37] tested the tribological behaviour of DLC coatings additionally with micro-texture.

Research on forming using volatile media as a lubricant that has recently appeared is worth attention. Umlauf et al. [38] and Reichardt et al. [39] developed a new tribological system for deep drawing processes in which nitrogen or carbon dioxide are introduced directly into the tools during forming and evaporate without residue after the process. It seems to be a very promising method which in future may completely eliminate lubricants from sheet forming.

In the present manuscript, the authors propose replacing conventional mineral/synthetic lubricants for sheet metal forming with ones based on vegetable oils and boric acid.

\section{Aim and range of tests}

The authors' experience to date has shown that vegetable oil-based lubricants are very useful in forming aluminium and titanium sheets [40]. The main goal of the present work is to assess the effectiveness of a vegetable oil-based lubricant with an additive of boric acid in reducing frictional resistance during the forming of steel drawn parts. The study was performed on $1.4021(2 \mathrm{H} 13, \mathrm{X} 20 \mathrm{Cr} 13)$ stainless steel sheets used in the Chirmed company-a manufacturer of surgical and medical instruments. The chemical composition and mechanical properties of the steel are, respectively, presented in Tables 1 and 2.

At the beginning, the lubricant effectiveness was assessed based on the strip drawing test, typically used in sheet metal forming (see Fig. 1). In order to perform the tests a special device of own construction was mounted in the tensile testing machine. In the tests the sheet metal strips with dimensions $1000 \times 20 \times 1 \mathrm{~mm}$ were drawn through a 
Table 1 Chemical composition of 1.4021 steel

\begin{tabular}{lllllll}
\hline Steel & \multicolumn{1}{l}{ Element } & & & \\
\cline { 2 - 7 } & \multicolumn{1}{l}{ Weight percentage (\%) } & & & \\
\cline { 2 - 7 } & $\mathrm{C}$ & $\mathrm{Si}$ & $\mathrm{Mn}$ & $\mathrm{P}$ & $\mathrm{S}$ & $\mathrm{Cr}$ \\
\hline 1.4021 & 0.204 & 0.47 & 0.64 & 0.015 & 0.001 & 13.36 \\
X20Cr13 & & & & & & \\
\hline
\end{tabular}

Table 2 Mechanical properties of 1.4021 steel

\begin{tabular}{lr}
\hline Tensile strength $R_{\mathrm{m}}(\mathrm{MPa})$ & 633 \\
$0.2 \%$ proof stress $R_{\mathrm{p} 02}(\mathrm{MPa})$ & 336 \\
Elongation $A_{50}(\%)$ & 40 \\
\hline
\end{tabular}

pair of hydraulic grips. The grips are made of NC10 steel. The working surfaces of the grips are flat with hardness of $58.5 \mathrm{HRC}$ and roughness parameters: $R_{\mathrm{a}}=0.16 \mu \mathrm{m}$ and $R_{\mathrm{z}}=0.9 \mu \mathrm{m}$. The initial roughness of the sheet metal (sample) was $R_{\mathrm{a}}=0.13 \mu \mathrm{m}$ and $R_{\mathrm{z}}=1.57 \mu \mathrm{m}$. The drawing speed was $100 \mathrm{~mm} / \mathrm{min}$.

The test stand enables measurement of the drawing force $F_{\mathrm{d}}$ as a function of blank holder force $F_{\mathrm{b}}$ exerted by the tool working parts (grips) on the sheet metal strip. The blank holder force $F_{\mathrm{b}}$ was calculated on the basis of the pressure measured in the working system of the device. Based on the measurements of the forces, the coefficient of friction $\mu$ was calculated, according to Amontons' law of friction, which declares that there is a proportionality between the frictional force $F_{\mathrm{f}}$ and the applied load—blank holder force $F_{\mathrm{b}}$. So the friction coefficient was calculated from the formula:

$\mu=\frac{F_{\mathrm{f}}}{F_{\mathrm{b}}}$.

Because the drawing force $F_{\mathrm{d}}$, recorded by the testing machine, balances the frictional resistance on the contact surfaces of the sheet metal strip with the steel grips (Fig. 1b), the drawing force $F_{\mathrm{d}}=2 \cdot F_{\mathrm{f}}$, hence $F_{\mathrm{f}}=F_{\mathrm{d}} / 2$, so

$\mu=\frac{F_{\mathrm{d}}}{2 F_{\mathrm{b}}}$.

The tests were carried out in technically dry friction conditions, i.e. without lubrication, and in the presence of technological lubricants. The following lubricants were tested:

- commercial lubricants: CL1, CL2, CL3

- rapeseed oil-RO

- rapeseed oil with boric acid-ROB

Moreover, the lubricant effectiveness was assessed during laboratory cupping tests with predominant stretching - the Erichsen test, and during cylindrical cupping in which the bottom of the cup is formed by stretching and a cylindrical wall is mainly formed by drawing. The Erichsen cupping test was performed according to PN-EN ISO 20482 standard. A ball punch with diameter of $20.0 \mathrm{~mm}$ was pushed into the square samples of $60 \times 60 \times 1 \mathrm{~mm}$ until fracture occurred. An inner diameter of the drawing die was $27.0 \mathrm{~mm}$ while the inner diameter of the blank-holder was $33.0 \mathrm{~mm}$.

To perform cylindrical cupping a flat bottom cylindrical punch with diameter of $33.6 \mathrm{~mm}$ and fillet radius of $2.5 \mathrm{~mm}$ was pushed into the sheet metal discs with diameter of $55.0 \mathrm{~mm}$ and thickness of $1 \mathrm{~mm}$, which were placed on a die with an inner diameter of $35.8 \mathrm{~mm}$ and fillet radius of
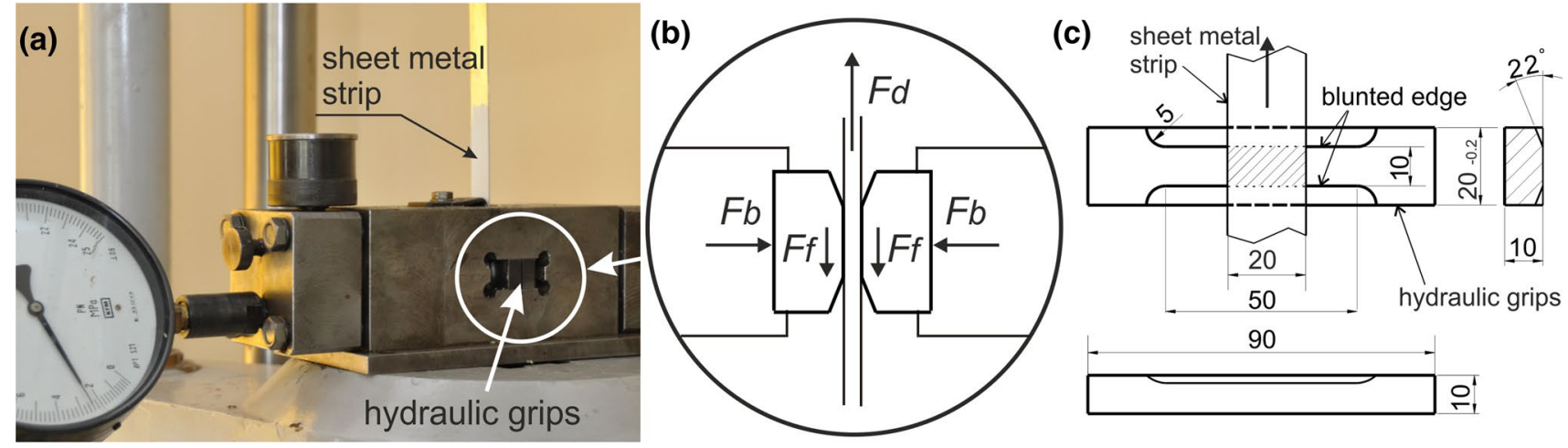

Fig. 1 Strip drawing test stand: a view of device, $\mathbf{b}$ scheme of strip-drawing test: $F_{d}$ drawing force, $F_{b}$ blank holder force, $F_{f}$ frictional force, $\mathbf{c}$ shape and dimensions of grips 
$3.5 \mathrm{~mm}$. The blank was pressed against the die by a blank holder with the inner diameter of $34.6 \mathrm{~mm}$.

Finally, the vegetable oil-based lubricants were assessed in industrial conditions, i.e. during manufacturing of the drawn parts as shown in Fig. 2.

The handle components are formed in four operations: initial (1st operation) and final (2nd operation) forming followed by trimming (3rd operation) and joining (4th operation) two halves into one unit.

\section{Vegetable oil with boric acid additive}

In sheet metal forming different lubrication mechanisms are used, from hydrodynamic to boundary lubrication where a very thin film of lubricant is adsorbed on the surface by physical or chemical forces or both. In a thick film lubrication some lubricant particles strongly adhere to the metal surface, while the remaining particles are loosely arranged away from rubbing surfaces. Then frictional resistance depends on the internal resistance between the lubricant particles moving over each other. The thick layer of lubricant protects against direct surface to surface contact until excess of lubricant is squeezed out of the space between the rubbing surfaces due to high unit pressure. Then, the boundary lubrication mechanism takes place, in which the main role is played by a very thin lubricant layer bound with the metal surface by physical action. This mechanism is like that as depicted in Fig. 3. Some lubricating additives increase the physical activity of lubricants, resulting in increased adsorption of fatty acid chains to the metal surface. When the physical interaction of lubricant particles can no longer provide the necessary film thickness, extreme pressure additives like chlorine, phosphorus or sulphur compounds (a) 1st operation - initial forming

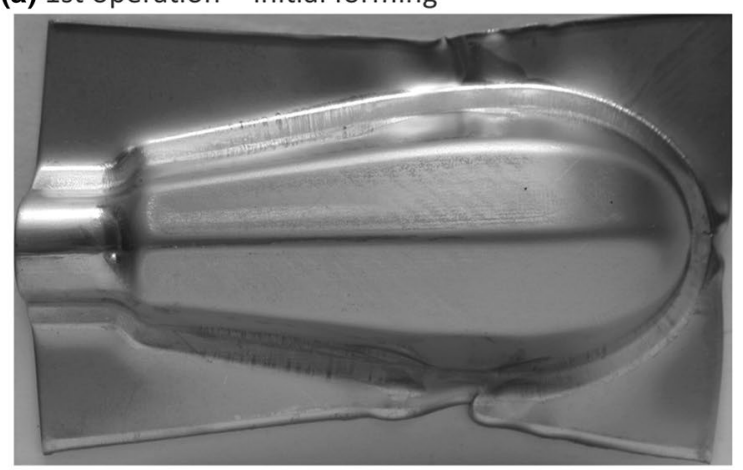

(c) $3^{\text {rd }}$ operation - trimming

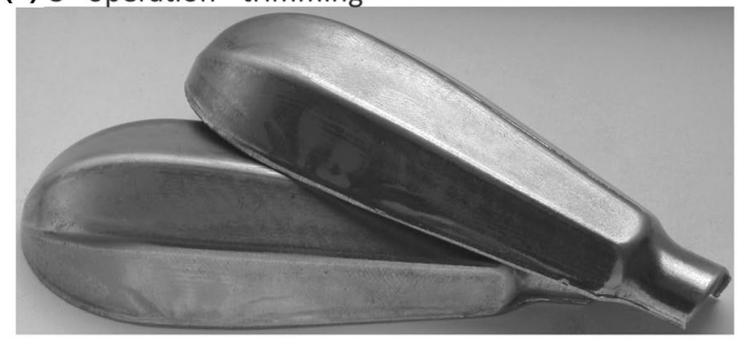

(e) final part (b) 2nd operation - final forming

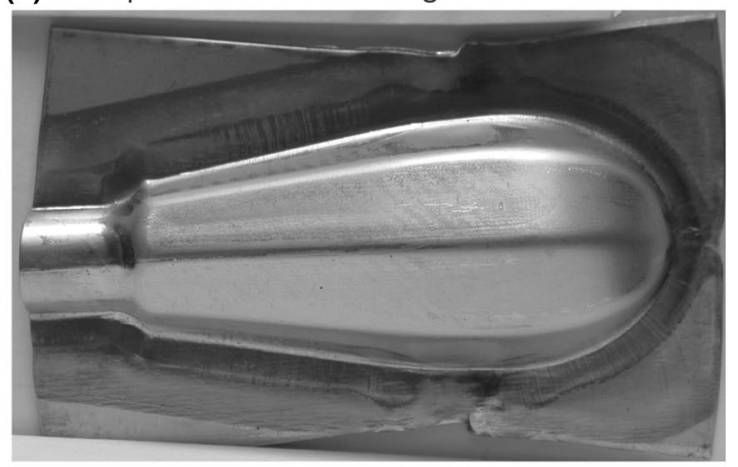

(d) $4^{\text {th }}$ operation - joining (welding)

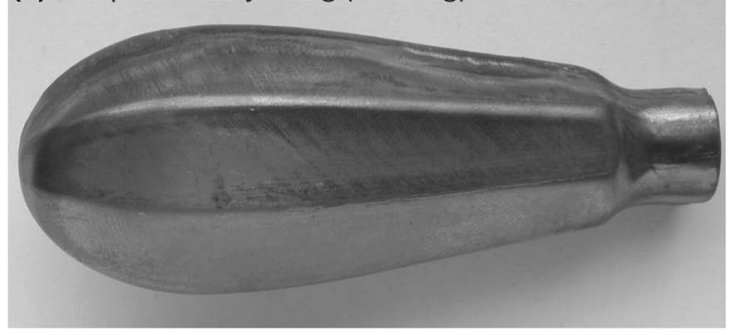

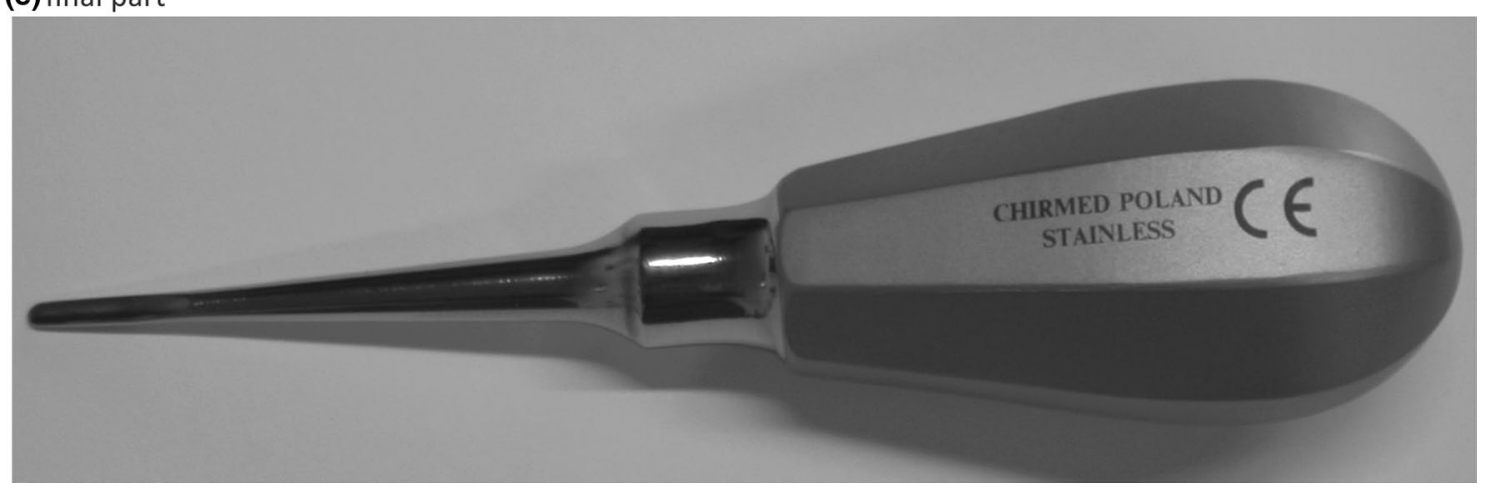

Fig. 2 Stages of forming gripping parts of surgical tools 
Fig. 3 Orientation of fatty acid molecules on metal surface (developed according to [41])
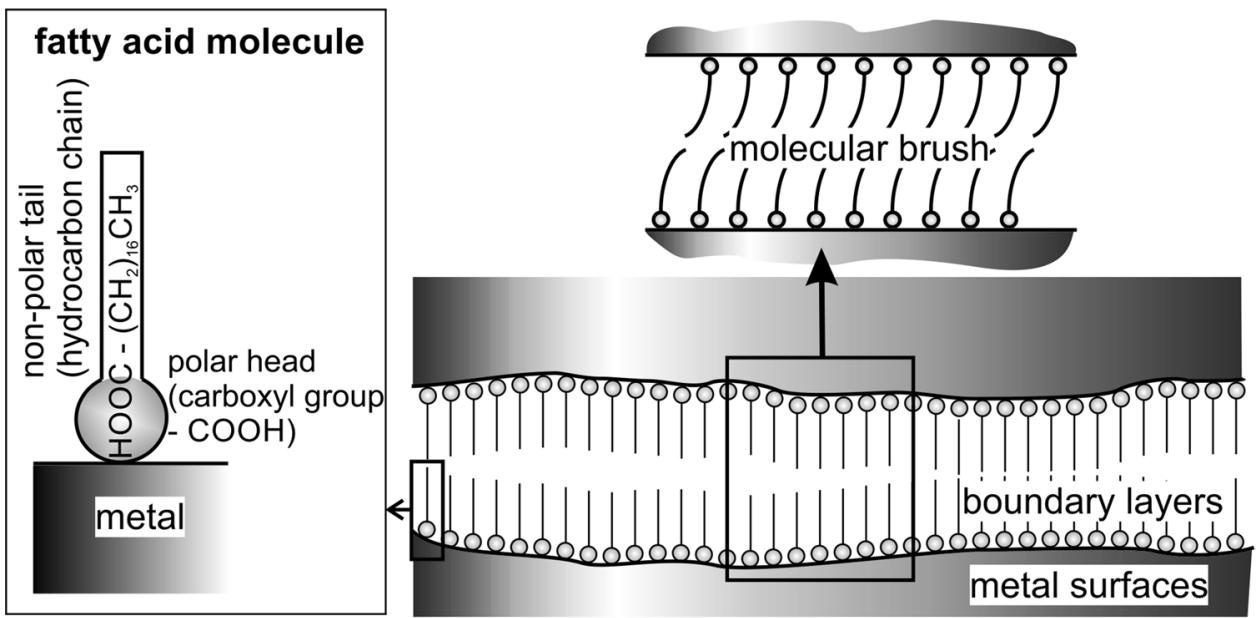

are added to the lubricating liquids which chemically react with metal asperities to form a durable antiadhesive film. Molybdenum disulphide and graphite are also widely used as anti-wear additives or dry lubricants. In this case, the lubrication mechanism is attributed to a layered structure at the molecular level. Poor bonds between layers facilitate sliding of the layers relative to each other, thereby ensuring a low coefficient of friction.

The elaboration of a recipe for an environmentally friendly lubricant that would reduce the forming resistance, at least to the same extent as in the case of commonly used lubricants based on mineral oils was the main assumption when developing lubricant for sheet metal forming. Rapeseed oil was accepted as the basis for the technological lubricant as it is readily available in Poland and relatively inexpensive. The good boundary lubrication of vegetable oils comes from their long polar fatty acid chains which are attached and perpendicularly oriented to the metal surface, as presented in Fig. 3. The monolayer film looking like a molecular brush reduces friction and wear. The longer the hydrocarbon chain, the greater the distance between the rubbing surfaces and stronger reduction in their interaction.

The tribological properties of rapeseed oil were enhanced by boric acid $\left(\mathrm{H}_{3} \mathrm{BO}_{3}\right)$, whose crystal structure is similar to that of graphite (Fig. 4). Graphite is commonly used as a solid lubricant or additive to oils. The layered structure of boric acid reduces friction, and in contrast to graphite, does not pollute the drawn part surfaces. The good lubricating properties come from the weak van der Waals bonds between the individual layers and strong covalent bonds within the layer. This enables easy sliding of one layer over another during tangential loading.

Similar to rapeseed oil, boric acid is easily accessible, inexpensive and more importantly, environmentally safe. The Environmental Protection Agency has established that boric acid is benign [42] and the Clean Water Act does not classify it as a pollutant [22].

Due to low solubility of boric acid in oils, during sheet forming it was used in accordance to the author's patent № PL229731 dated on 21.10.2014 [43]. Rapeseed oil and boric acid are subsequently sprayed onto the sheet surface. Boric acid particles are physically adsorbed on the tool and sheet surfaces covered with a thin (100-180 $\mu \mathrm{m})$ oil film, creating a layer to which further boric acid particles are attracted until the whole surface roughness is filled. From this moment, mutual displacement of the rubbing surfaces takes place in the acid layer along planes of easy slip. As a result, the coefficient of friction is significantly reduced. The
Fig. 4 Layered crystal structure: a graphite, $\mathbf{b}$ boric acid (developed according to [6])
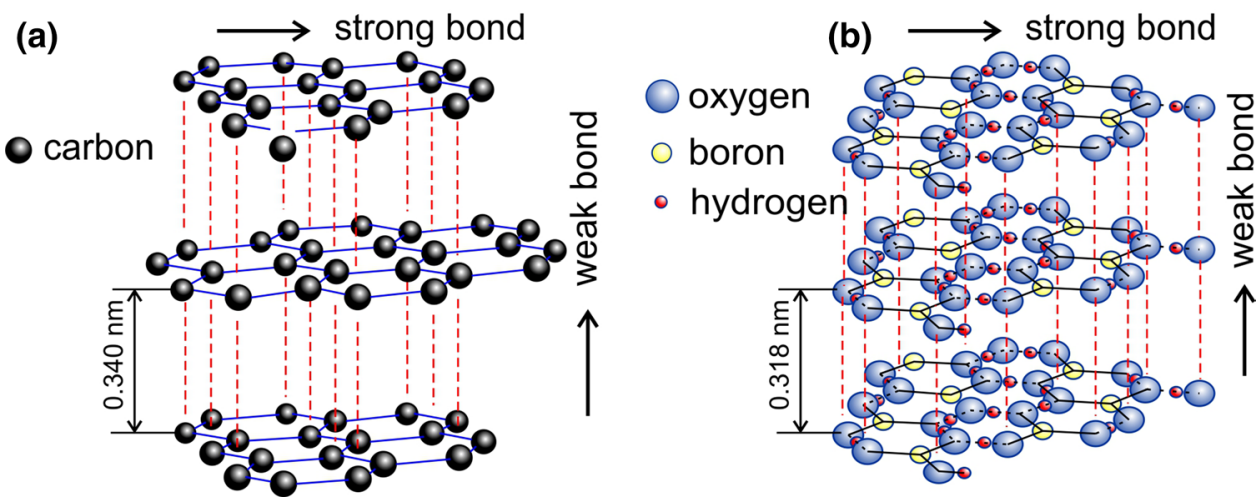
scheme of lubrication with the vegetable oil-based lubricant with an additive of boric acid is presented in Fig. 5.

The lubricating mechanism of ROB lubricant includes both strong adsorption of long polar fatty acid chains to metal surface and easy slipping of boric acid crystal layers relative to each other.

The development of this lubrication technology is a part of the strategy to use "green lubricants", which aims to reduce or completely eliminate petroleum-based products from sheet metal forming. In addition to their excellent lubricating properties, lubricants based on vegetable oils with a boric acid additive do not require expensive disposal techniques.

\section{Test results and discussion}

\subsection{Strip drawing test}

During drawing of the sheet metal strips between the flat grips of the tool, just like in the sheet metal forming process, there is a mechanical and molecular interaction between the materials of the working tool surfaces and the sheet metal in relative motion. In the absence of lubrication, due to the mechanical impact of the tool on the sheet metal surface, significant plastic deformation and smoothing of microunevenness occurs. Unfortunately, the low sliding speeds and significant proximity of the contacting surfaces favour the transfer of the deformed metal to the tool surfaces and its accumulation. Consequently, the accretions cause scratches and dents on the surface of the deformed sheets. These defects are caused by the formation (welding) and rupture of micro-junctions between the opposing asperities on the rubbing surfaces. As a result, the surface roughness of the sheet increases (Fig. 6) and the friction resistance grows. In

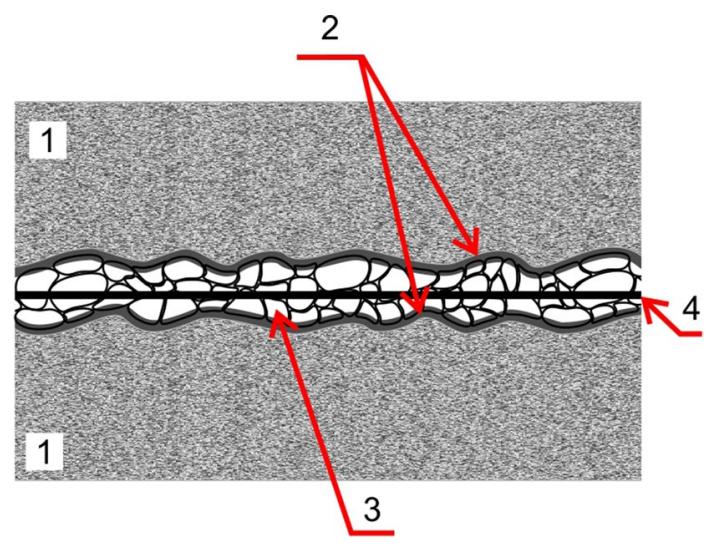

Fig. 5 Mechanism of lubrication with vegetable oil-based lubricant with additive of boric acid: (1) metal, (2) oil film, (3) filling of surface unevenness cavities with boric acid, (4) boric acid slip plane order to counteract this phenomenon, a technological lubricant is introduced between the rubbing surfaces. As long as the lubricant forms a continuous film, friction occurs in the lubricant layer and the deformed sheet surface is relatively smooth with no signs of wear. A break in the lubricating film results in an immediate increase in friction resistance. The ROB lubricant has proven to be particularly useful in separating rubbing surfaces, even at high unit pressures.

Roughness was measured perpendicularly to the length of the sheet metal strip as shown in Fig. 6.

The results of the strip drawing test carried out in dry conditions and with lubricants are presented in Fig. 7.

As is seen from Fig. 7, the worst results were obtained for the CL1 lubricant, which is used in the production technology in the Chirmed company. It slightly reduces the coefficient of friction in comparison to strip drawing with no lubricant at unit pressures greater than $20 \mathrm{MPa}$; however, above $35 \mathrm{MPa}$ the CL1 lubricating film breaks and the coefficient of friction increases. The rapeseed oil with the additive of boric acid is the most effective lubricant, for which the mean coefficient of friction value is 0.03 . The additive of boric acid to the rapeseed oil reduces the coefficient of friction about six times. The rapeseed oil with the additive of boric acid is also better than the other tested commercial lubricants for sheet metal forming, for which the coefficients of friction are as follows: 0.08 for CL2 and 0.13 for CL3. What is more, the film of rapeseed oil with boric acid does not break even at a high unit pressure and effectively protects the sheet surface against scratches.

\subsection{Erichsen cupping test}

During the Erichsen cupping test, the sheet undergoes thinning as a result of biaxial stretching. The lack of friction causes the greatest sheet thinning in the central part of the cup; therefore the crack initiates at its pole and runs meridionally. Friction between the sheet and the punch counteracts sheet thinning (counteracts the flow of individual material points), hence the crack initiates at a certain distance from the cup pole and runs in a circumferential direction. The greater the share of friction forces between the punch and the formed sheet, the further the groove forms, and consequently the crack. During the Erichsen cupping test the cup height at the fracture moment of the sheet as well as the distance between the cup axis and circumferential fracture were recorded. The test results are presented in Figs. 8 and 9 .

According to Figs. 8 and 9, the use of rapeseed oil with an additive of boric acid increased the cup height at the fracture moment and the fracture location indicates a significant reduction in friction. Obtaining deeper cups is possible thanks to more even strain distribution in the sheet material. The results of forming in the presence of other lubricants were comparable with forming in dry conditions. In spite 


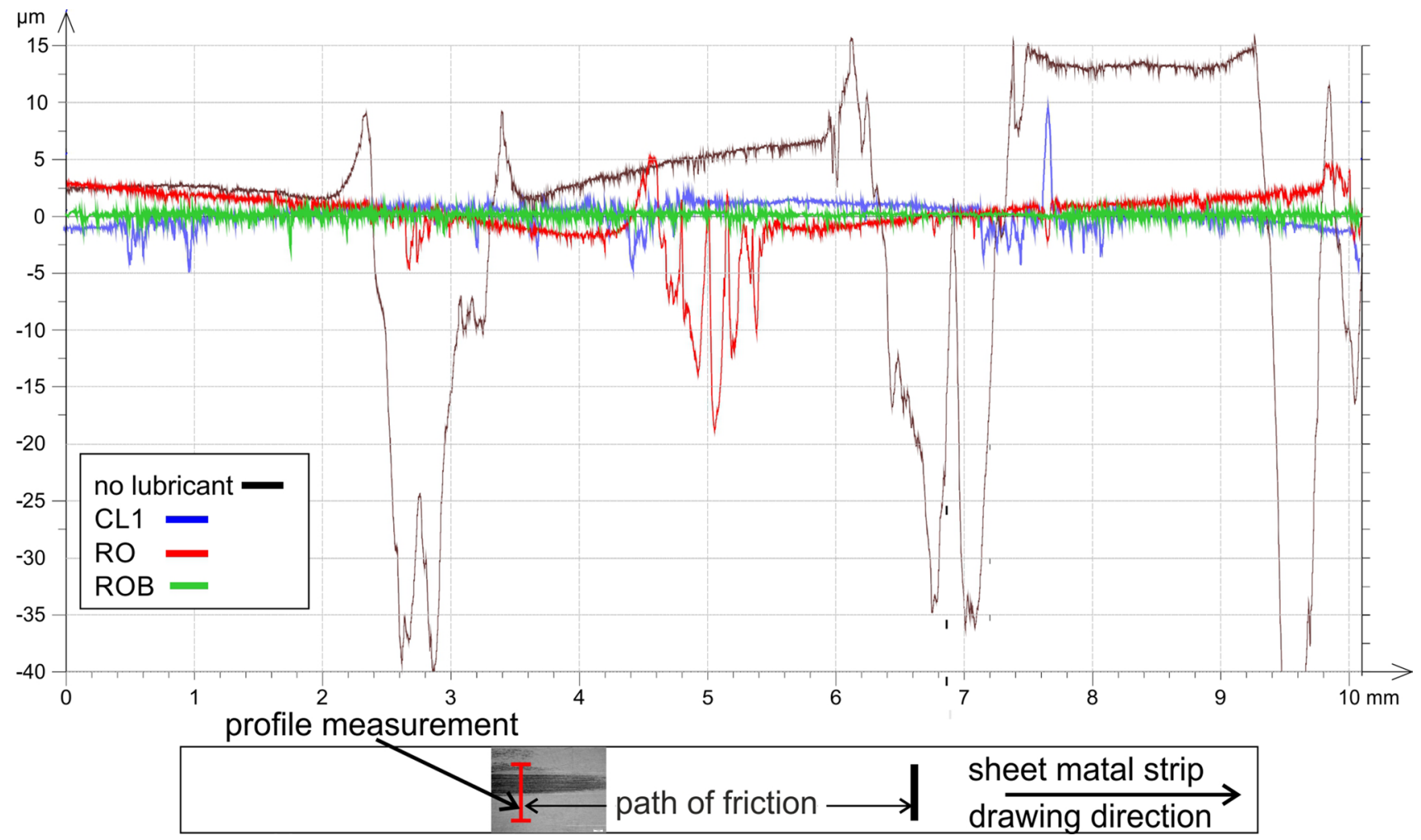

Fig. 6 The roughness of the deformed sheet after the strip drawing test; unit pressure: $40 \mathrm{MPa}$, path of friction: $0.3 \mathrm{~m}$

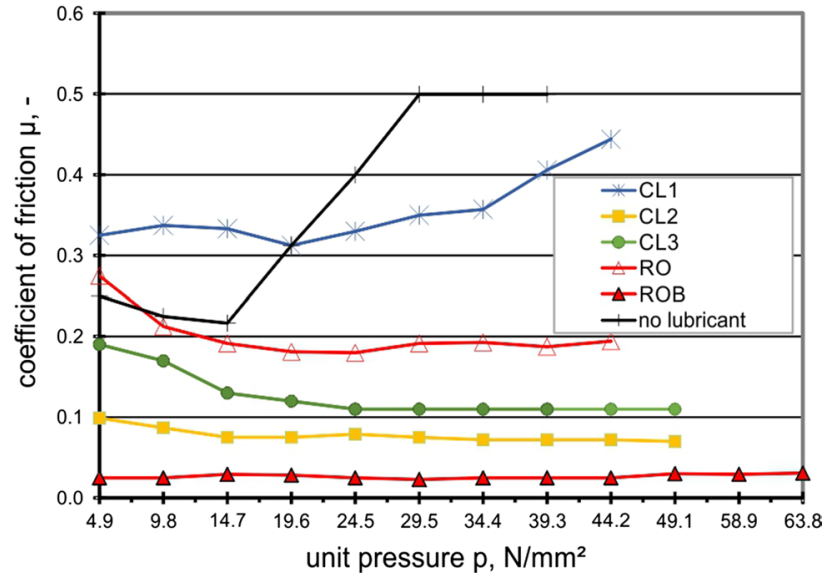

Fig. 7 Coefficient of friction vs unit pressure

of this, lubrication is necessary because each subsequent forming operation increases the risk of build-up formation on the tool surface and the tendency to galling.

\subsection{Cylindrical cupping test}

The process of forming cylindrical cups was assessed based on the maximal forming force and appearance of the cup surface. The cups were formed in a hydraulic double-acting device for cupping tests. The tool consists of a punch, a die and a blank holder. Blank holder forces of 5 and $15 \mathrm{kN}$ were applied. The test results are presented in Figs. 10 and 11.

Figure 10 shows that the ROB lubricant is the most effective, causing a decrease in the forming force in comparison to forming without lubricant of $12 \%$ or $23 \%$, respectively, for the blank holder force of 5 and $15 \mathrm{kN}$. In comparison to forming with other lubricants, the use of ROB on average reduces the forming force by $11 \%$ for the blank holder force of $5 \mathrm{kN}$ and $18 \%$ for the blank holder force of $15 \mathrm{kN}$. In the case of forming with the CL1 lubricant, the maximum forming force was similar to forming with no lubricant. The forming force for the other lubricants (CL2, CL3 and RO) is at a similar level, i.e. $44 \mathrm{kN}$ and $48 \mathrm{kN}$, respectively, for the blank holder force of 5 and $15 \mathrm{kN}$.

During forming without lubrication and in the presence of the CL1 (presently used in the factory) lubricant, build-up of the deformed material on the die surface was observed. It resulted in vertical scratches on the side wall of the cup. The smoothest surface was received in case of cup forming in the presence of the ROB lubricant. This lubricant effectively separates the contact surfaces and prevents the formation of build-up on the working surfaces of the tool. This lubricant has the highest influence on a decrease in the forming force. 
Fig. 8 The cup height at the onset of fracture in the Erichsen cupping test

Fig. 9 The view of cups after the Erichsen cupping test
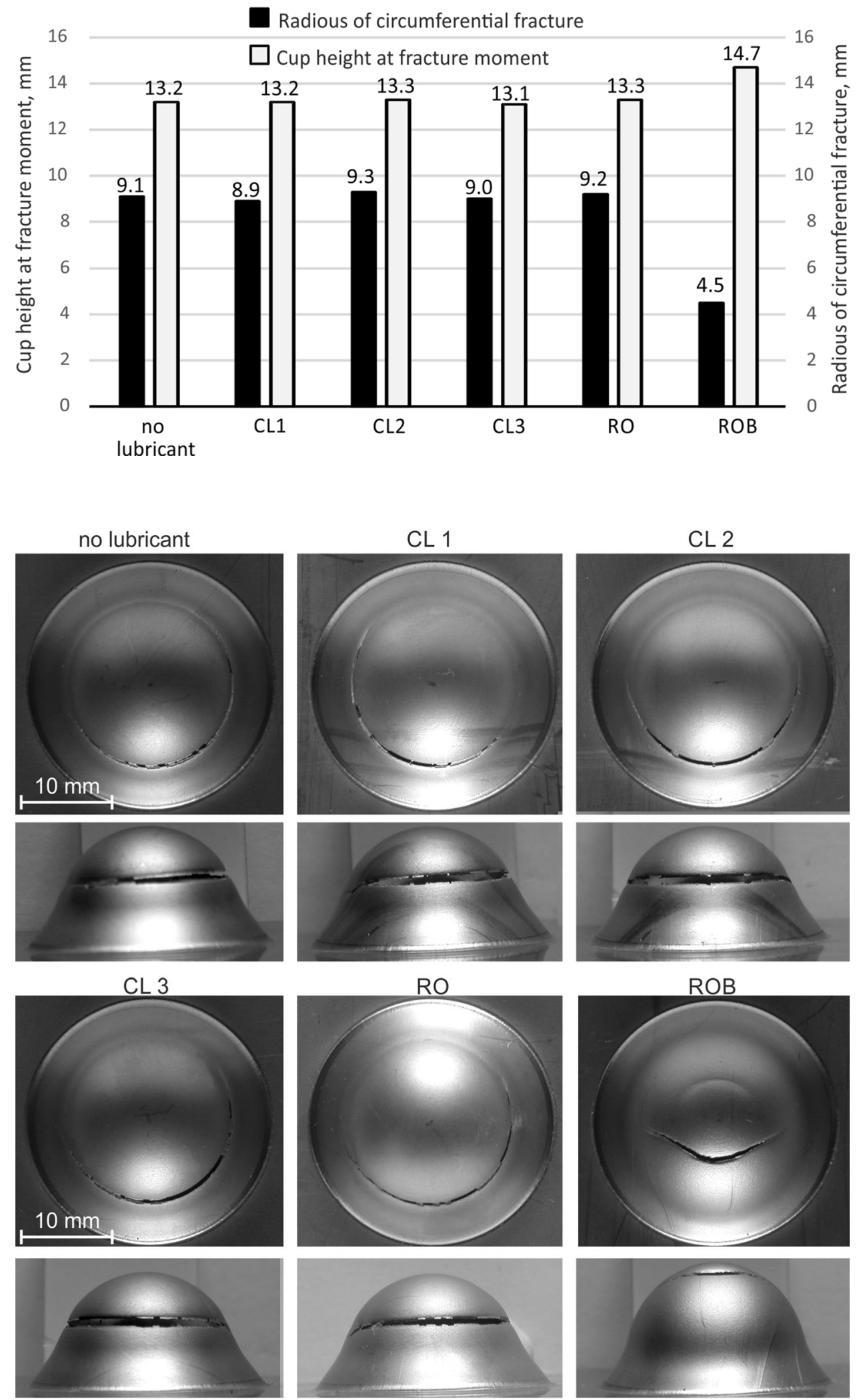


\subsection{Industrial testing}

To date, CL1 lubricant was used in the Chirmed company during cup forming-halves of gripping parts of surgical tools. Laboratory tests showed that the CL1 lubricant has the worst tribological properties among the tested lubricants. The lubricant does not separate the deformed material and tool enough; therefore the surfaces of the produced parts are uneven, sometimes with wrinkling or even fracture (see Fig. 12a).

Replacing the CL1 lubricant with the ROB one significantly improved the quality of the cup surfaces. Wrinkling and cracks were eliminated, and the surface was smoother.

Now, testing is directed at producing the final cups in one operation. The initial tests showed that applying the
Fig. 10 The results of the cylindrical cupping test
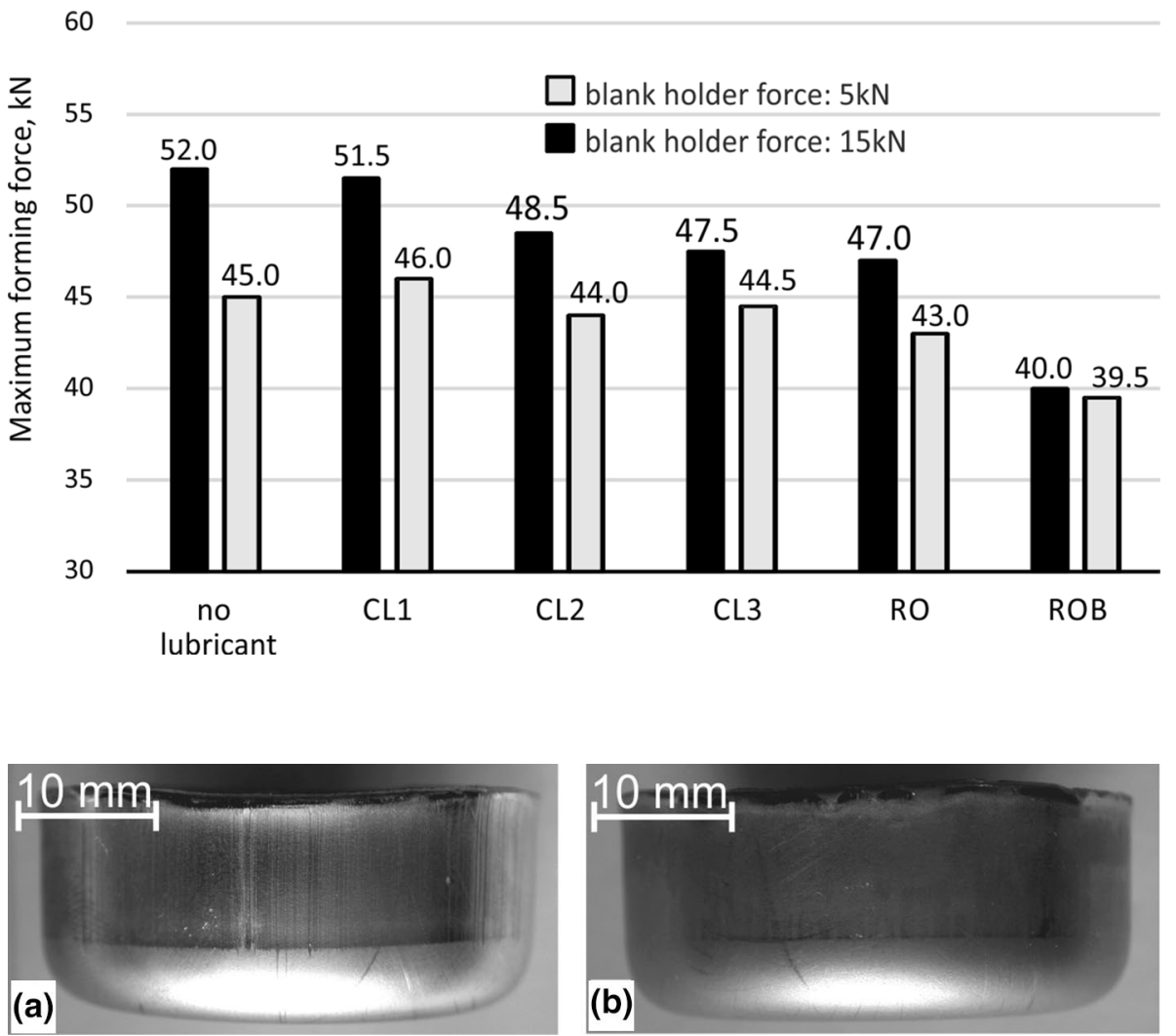

Fig. 11 View of cups formed with: a CL1, b ROB; blank holder force: $15 \mathrm{kN}$ (a)
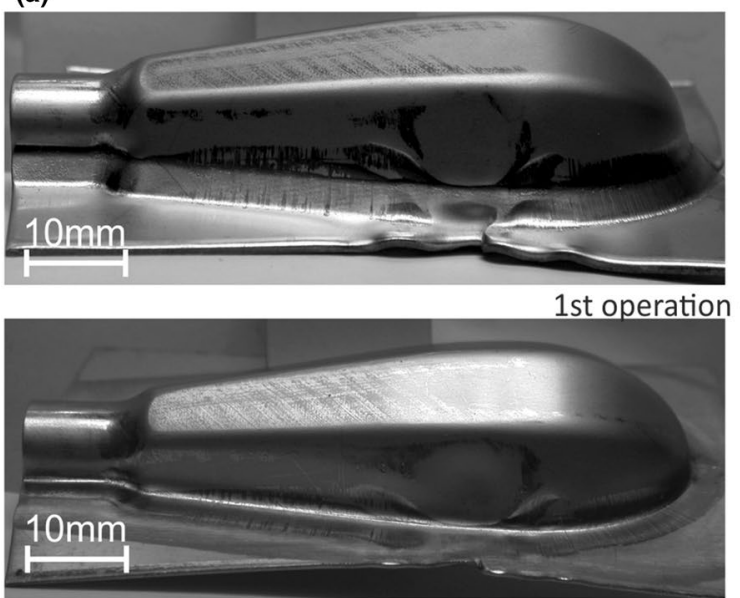

(b)

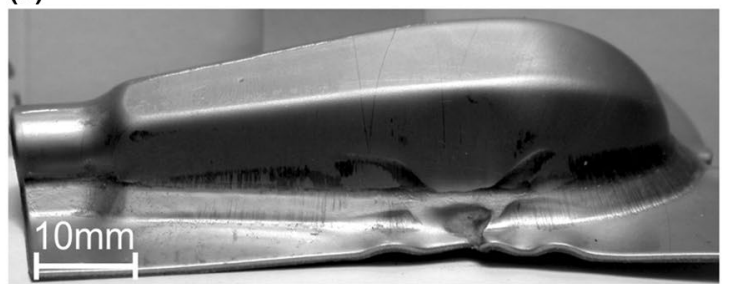

initial forming

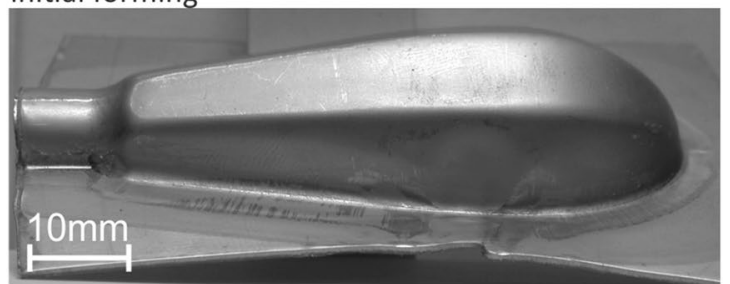

2nd operation - final forming

Fig. 12 Comparison of cup surfaces: a forming with CL1 lubricant, b forming with ROB lubricant 
Fig. 13 Comparison of cups formed in 1 operation: a forming with CL1 lubricant, $\mathbf{b}$ forming with ROB lubricant (a)

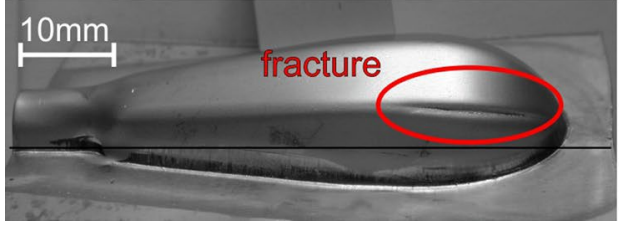

(b)

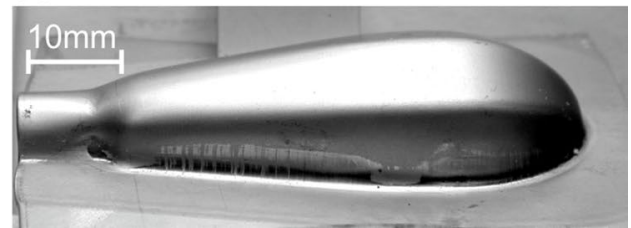

ROB lubricant caused a more even strain distribution, and as a result fractures (Fig. 13a) were eliminated.

It is expected that adopting the formation of cups in one operation will significantly reduce production costs.

\section{Conclusions}

Based on the experimental tests, it can be stated that:

- friction and lubrication significantly affect the strain distribution in the drawn parts as evidenced by the nature of the crack in the Erichsen cupping test (Fig. 9),

- the oil-based lubricant with the additive of boric acid was the most effective lubricant among the tested lubricants-it significantly reduced the forming force and frictional resistance, as well as improved the smoothness of the drawn part surfaces,

- rapeseed oil with the additive of boric acid caused a decrease in the coefficient of friction from $\mu \approx 0.37$ for forming without lubrication and from 0.13 for the CL3 or 0.07 for CL2 lubricant to 0.03 (Fig. 7).

- the film of boric acid maintained good tribological properties even at a high unit pressure, while the other tested lubricant films broke (Fig. 7).

Moreover, rapeseed oil with the additive of boric acid is friendly to the environment.

Acknowledgements Financial support of Structural Funds in the Operational Programme-Innovative Economy (IE OP) financed from the European Regional Development Fund-Project "Modern material technologies in aerospace industry", Nr POIG.01.01.02-00-015/0800 is gratefully acknowledged. The authors also thank CHIRMEDManufacturer of Surgical and Medical Instruments for their support in preparing the samples and performing industrial tests.

Open Access This article is licensed under a Creative Commons Attribution 4.0 International License, which permits use, sharing, adaptation, distribution and reproduction in any medium or format, as long as you give appropriate credit to the original author(s) and the source, provide a link to the Creative Commons licence, and indicate if changes were made. The images or other third party material in this article are included in the article's Creative Commons licence, unless indicated otherwise in a credit line to the material. If material is not included in the article's Creative Commons licence and your intended use is not permitted by statutory regulation or exceeds the permitted use, you will need to obtain permission directly from the copyright holder. To view a copy of this licence, visit http://creativecommons.org/licenses/by/4.0/.

\section{References}

1. Gronostajski Z, Pater Z, Madej L, Gontarz A, Lisiecki L, Lukaszek-Solek A, Luksza J, Mróz S, Muskalski Z, Muzykiewicz W, Pietrzyk M, Sliwa RE, Tomczak J, Wiewiórowska S, Winiarski G, Zasadziński J, Ziółkiewicz S. Recent development trends in metal forming. Arch Civ Mech Eng. 2019;19(3):898-941. https ://doi.org/10.1016/j.acme.2019.04.005.

2. Adamus J. Lubrication in sheet-metal forming processes, XXV Silver Jubilee School of Tribology: Tribology on the Threshold of the Third Millenium; 2002 Sep 23-26; Ladek Zdroj, Poland. Scientific Papers of the Institute of Machine Design and Operation of the Technical University of Wroclaw 87/27; 2002. pp. 15-20.

3. Adamus J. The influence of friction and lubrication on sheetaluminium forming process. Tribology and lubrication engineering: 14th International Colloquium Tribology; 2004 Jan 13-15; Ostfildern, Germany. Technische Akademie Esslingen; 2004. pp. 1813-18.

4. Wilson WRD. Tribology in cold metal forming. J Manuf Sci Eng. 1997;119(4B):696-8. https://doi.org/10.1115/1.2836811.

5. Zareh-Desari B, Davoodi B. Assessing the lubrication performance of vegetable oil-based nano-lubricants for environmentally conscious metal forming processes. J Clean Prod. 2016;135:1198209. https://doi.org/10.1016/j.jclepro.2016.07.040.

6. Lovell M, Higgs CF, Deshmukh P, Mobley A. Increasing formability in sheet metal stamping operations using environmentally friendly lubricants. J Mater Process Technol. 2006;177(1):87-90. https://doi.org/10.1016/j.jmatprotec.2006.04.045.

7. Zhenglin T, Shaohui L. A review of recent developments of friction modifiers for liquid lubricants (2007-present). Curr Opin Solid State Mater Sci. 2014;18(3):119-39. https://doi. org/10.1016/j.cossms.2014.02.002.

8. Pena-Paras L, Gutiérrez J, Irigoyen M, Lozano M, Velarde M, Maldonado-Cortes D, Taha-Tijerina J. Study on the anti-wear properties of metal-forming lubricants with $\mathrm{TiO}_{2}$ and $\mathrm{CuO}$ nanoparticle additives. IOP Conf Ser Mater Sci Eng. 2018;400:062022. https://doi.org/10.1088/1757-899X/400/6/062022.

9. Azman NF, Samion S, Sot MNHM. Investigation of tribological properties of $\mathrm{CuO} /$ palm oil nanolubricant using pin-on-disc tribotester. Green Mater. 2018;6(1):30-7. https://doi.org/10.1680/ jgrma.17.00026.

10. Mosleh M, Atnafu ND, Belk JH, Nobles OM. Modification of sheet metal forming fluids with dispersed nanoparticles for improved lubrication. Wear. 2009;267(5):1220-5. https://doi. org/10.1016/j.wear.2008.12.074.

11. Maharaja K, Vijayan SN, Karthik S. Tribological effect of size, shape and structure of nanoparticle in lubricant oil-a review. In: International conference on systems, science, control, communication, engineering and technology (ICSSCCET 2016); 2016. 
pp. 730-34. https://www.researchgate.net/publication/317559536. Accessed 03 Sept 2019.

12. Kerni L, Raina A, Haq MIU. Friction and wear performance of olive oil containing nanoparticles in boundary and mixed lubrication regimes. Wear. 2019;426-427(A):819-27. https://doi. org/10.1016/j.wear.2019.01.022.

13. Wu H, Qina L, Dong G, Hua M, Yang S, Zhang J. An investigation on the lubrication mechanism of $\mathrm{MoS}_{2}$ nano sheet in point contact: the manner of particle entering the contact area. Tribol Int. 2017;107:48-55. https://doi.org/10.1016/j.triboint.2016.11.009.

14. Shahnazar S, Bagheri S, Hamid SBA. Enhancing lubricant properties by nanoparticle additives. Int $\mathbf{J}$ Hydrog Energy. 2016;41(4):3153-70. https://doi.org/10.1016/j.ijhyd ene.2015.12.040.

15. Holmberg K, Erdemir A. Influence of tribology on global energy consumption, costs and emissions. Friction. 2017;5(3):263-84. https://doi.org/10.1007/s40544-017-0183-5.

16. Dai W, Kheireddin B, Gao H, Liang H. Roles of nanoparticles in oil lubrication. Tribol Int. 2016;102:88-98. https://doi. org/10.1016/j.triboint.2016.05.020.

17. Sharma AK, Tiwari AK, Dixit AR, Singh RK, Singh M. Novel uses of alumina/graphene hybrid nanoparticle additives for improved tribological properties of lubricant in turning operation. Tribol Int. 2018;119:99-111. https://doi.org/10.1016/j.tribo int.2017.10.036.

18. Sharma AK, Katiyar JK, Bhaumik S, Roy S. Influence of alumina/ MWCNT hybrid nanoparticle additives on tribological properties of lubricants in turning operations. Friction. 2019;7(2):153-68. https://doi.org/10.1007/s40544-018-0199-5.

19. Rao KP, Wei JJ. Performance of a new dry lubricant in the forming of aluminum alloy sheets. Wear. 2001;249(1-2):86-93. https ://doi.org/10.1016/S0043-1648(01)00526-9.

20. Bay N, Azushima A, Groche P, Ishibashi I, Merklein M, Morishita M, Nakamura T, Schmid S, Yoshida M. Environmentally benign tribo-systems for metal forming. CIRP Ann Manuf Technol. 2010;59(2):760-80. https://doi.org/10.1016/j.cirp.2010.05.007.

21. Zainal NA, Zulkifli NWM, Gulzar M, Masjuki HH. A review on the chemistry, production, and technological potential of biobased lubricants. Renew Sustain Energy Rev. 2018;82(1):80-102. https ://doi.org/10.1016/j.rser.2017.09.004.

22. Lovell MR, Kabir MA, Menezes PL, Higgs CF. Influence of boric acid additive size on green lubricant performance. Philos Trans. 2010;368:4851-68. https://doi.org/10.1098/rsta.2010.0183.

23. Kirkhorn L, Gutnichenko O, Bihagen S, Stahl J-E. Minimum quantity lubrication (MQL) with carbon nanostructured additives in sheet metal forming. Proc Manuf. 2018;25:375-81. https://doi. org/10.1016/j.promfg.2018.06.106.

24. Rao KP, Prasad YVRK, Xie CL. Further evaluation of boric acid vis- a-vis other lubricants for cold forming applications. Tribol Int. 2011;44(10):1118-26. https://doi.org/10.1016/j.tribo int.2011.04.016.

25. Muaz M, Choudhury SK. Experimental investigations and multiobjective optimization of MQL-assisted milling process for finishing of AISI 4340 steel. Measurement. 2019;138:557-69. https:// doi.org/10.1016/j.measurement.2019.02.048.

26. Carcel AC, Palomares D, Rodilla E, Puig MA. Evaluation of vegetable oils as pre-lube oils for stamping. Mater Des. 2005;26(7):587-93. https://doi.org/10.1016/j.matdes.2004.08.010.

27. Padgurskas J, Rukuiža R, Meškinis A, Kreivaitis R, Spruogis B. Influence of manufacturing methods on the tribological properties of rapeseed oil lubricants. Transport. 2016;31(1):56-62. https:// doi.org/10.3846/16484142.2015.1048525.

28. Syahir AZ, Zulkifli NWM, Masjuki HH, Kalam MA, Alabdulkarem A, Gulzar M, Khuong LS, Harith MH. A review on bio-based lubricants and their applications. J Clean
Prod. 2017;168:997-1016. https://doi.org/10.1016/j.jclep ro.2017.09.106.

29. Woma TY, Lawal SA, Abdulrahman AS, Oluto MA, Ojapah MM. Vegetable oil based lubricants: challenges and prospects. Tribol Online. 2019;14(2):60-70. https://doi.org/10.2474/trol.14.60.

30. Więckowski W, Dyja K. The effect of the use of technological lubricants based on vegetable oils on the process of titanium sheet metal forming. Arch Metall Mater. 2017;62(2A):489-94. https:// doi.org/10.1515/amm-2017-0070.

31. Erdemir A. Chapter 22: Solid lubricants and self-lubricating films. Boca Raton: CRC Press LLC; 2001.

32. Gearing BP, Moon HS, Anand L. A plasticity model for interface friction: application to sheet metal forming. Int $\mathrm{J}$ Plast. 2001;17(2):237-71. https://doi.org/10.1016/S0749 $-6419(00) 00034-6$.

33. Hazrati J, Stein P, Kramer P, van den Boogaard AH. Tool texturing for deep drawing applications. IOP Conf Ser Mater Sci Eng. 2018;418:012095. https://doi.org/10.1088/1757899X/418/1/012095.

34. Taha-Tijerina JJ, Garza GT, Maldonado-Cortés D. Evaluation of parameters for application of Laser Surface Texturing (LST) in tooling for the sheet-metal forming process. Ind Lubr Tribol. 2018;70(4):620-7. https://doi.org/10.1108/ILT-07-2017-0194.

35. Adamus J, Lackner JM, Major $Ł$. A study of the impact of antiadhesive coatings on the sheet-titanium forming processes. Arch Civ Mech Eng. 2013;13:64-71. https://doi.org/10.1016/j. acme.2012.12.003.

36. Ghiottia A, Bruschi S. Tribological behaviour of DLC coatings for sheet metal forming tools. Wear. 2011;271(9-10):2454-8. https:// doi.org/10.1016/j.wear.2010.12.043.

37. Shimizu T, Kan H, Messaoudi H, Vollertsen F, Yang M. Geometrical design of micro-textured DLC coatings toward lubricant-free metal forming, MATEC Web of Conferences 190 (2018) 13001, In: 5th international conference on new forming technology (ICNFT 2018). https://doi.org/10.1051/matecconf/201819013001.

38. Umlauf G, Hasselbruch H, Henze JH, Barz J, Mehner A. A new approach for dry metal forming: $\mathrm{CO}_{2}$ as volatile lubrication in combination with hard and low friction coatings, MATEC Web of Conferences 190 (2018) 14012. In: 5th international conference on new forming technology (ICNFT 2018). https://doi. org/10.1051/matecconf/201819014012.

39. Reichardt G, Liewald M. Investigation on friction behaviour of deep drawing radii using volatile media as lubricant substitutes. Proc Manuf. 2019;29:193-200. https://doi.org/10.1016/j.promf g.2019.02.126.

40. Adamus J, Dyja K, Więckowski W. Lubricants based on vegetable oils as effective lubricating agents in sheet-titanium forming. Key Eng Mater. 2016;687:163-70. https://doi.org/10.4028/www.scien tific.net/KEM.687.163.

41. Hebda M, Wachal A. Tribology (in Polish: Trybologia). Warsaw: Scientific and Technical Publishing House-WNT; 1980.

42. Krishna PV, Srikant RR, Rao DN. Experimental investigation on the performance of nanoboric acid suspensions in SAE-40 and coconut oil during turning of AISI 1040 steel. Int J Mach Tools Manuf. 2010;50:911-6. https://doi.org/10.1016/j.ijmachtool s.2010.06.001.

43. Patent No PL229731 dated on 2014.10.21, Method of applying lubricant on surface of sheet made of hard to deform material before cold sheet metal forming.

Publisher's Note Springer Nature remains neutral with regard to jurisdictional claims in published maps and institutional affiliations. 